\title{
SEMEADURA DIRETA DE CANAFÍSTULA (Peltophorum dubium (Spreng.)Taub. NO ENRIQUECIMENTO DE CAPOEIRAS ${ }^{1}$
}

\author{
Vilmar Luciano Mattei² e Mariane D’Avila Rosenthal ${ }^{3}$
}

\begin{abstract}
RESUMO - O presente trabalho teve por objetivo avaliar o comportamento da canafistula (Peltophorum dubium), em semeadura direta a campo, em área de capoeira originada após o abandono do local utilizado com cultivos agrícolas sucessivos. No local foram roçadas faixas de $1,5 \mathrm{~m}$, a cada $3 \mathrm{~m}$. A semeadura foi realizada em setembro de 1997. Visando proteger os pontos semeados, foram utilizados diferentes tipos de protetores (copos de plástico e copos de papel, sem fundo e laminado de madeira), fixados sobre os pontos semeados com três sementes cada. As sementes foram escarificadas mecanicamente a $1.725 \mathrm{rpm}$, durante 60 segundos, com lixa Norton 60 . O delineamento foi em blocos casualizados, com seis repetições. As variáveis avaliadas foram emergência, sobrevivência, número de pontos com plantas, densidade a 1 ano e altura das plantas aos 18 meses. Os resultados obtidos aos nove meses demonstraram que a utilização de qualquer um dos protetores físicos contribuiu para o estabelecimento de plantas em mais de $80 \%$ dos pontos semeados, e em mais de $75 \%$, um ano após a semeadura, quando utilizado o laminado, o que indica que a semeadura direta é uma alternativa de implantação para a espécie, possibilitando transformar as áreas de capoeiras em um sistema agroflorestal ou mesmo silvipastoril, no futuro.
\end{abstract}

Palavras-chave: Semeadura direta, Peltophorum dubium, protetores de semeadura e enriquecimento de capoeiras.

\section{DIRECT SEEDING OF CANAFISTULA (Peltophorum dubium (Spreng.) Taub. TO REGENERATE SHRUBS}

\begin{abstract}
This work aimed to evaluate the development of Peltophorum dubium by direct seeding on a succesively cropped field. Seeding was performed in rows of $1.5 \mathrm{~m}$, three meters apart, on September 1977. To protect the seed-spots shelters, bottomless paper and plastic cups were used and wood slates were fixed on them. Seeds were mechanically scarified for 60 seconds. The variables evaluated were emergence, seedling survival, number of seed-spots with plants plant density at one year and plant height at the $18^{\text {th }}$ month. Results at the $9^{\text {th }}$ month showed that the seed-spot shelters contributed for plant establishment in $80 \%$ of the seed-spots and in more than $75 \%$ of them one year after seeding, when wood slates were used. Direct seeding is a viable alternative for this species which will allow the transformation of shrub areas into an agroforest or even silvipastural system in the near future.
\end{abstract}

Key words: $\quad$ Direct seeding, Peltophorum dubium, seed-spot shelters and shrub regeneration.

\section{INTRODUÇÃO}

O Estado do Rio Grande do Sul possuía, originalmente, $42 \%$ de sua superfície territorial coberta com florestas. Já no início do século XX, foi reduzida para aproximadamente $25 \%$, chegando a apenas $4 \% \mathrm{em}$ 1965. As poucas áreas nativas existentes restringem-se às áreas de preservação, aos parques, às reservas e aos

1 Recebido para publicação em 18.10.2000.

Aceito para publicação em 03.12.2002.

Trabalho financiado pelo CNPq/FAPERGS.

${ }^{2}$ Eng.-Agr. Dr. em Ciência Florestal - Prof. de Silvicultura da FAEM/UFPEL, Caixa Postal 354 Campus, 96010-900 PELOTASRS, <vlmattei@ufpel.tche.br>; ${ }^{3}$ Eng.-Agr. Doutoranda em Ciência e Tecnologia de Sementes FAEM/UFPEL, <marianer@ufpel.tche.br>. 
pequenos porcentuais em áreas de difícil acesso. Nas propriedades rurais existem pequenos remanescentes, em sua grande maioria parcialmente explorados.

Essa ação resultou na ameaça de extinção de muitas espécies de grande valor e de interesse econômico, entre elas a canafístula, e consequientemente de toda a mata e dos representantes da fauna que dependem delas para se manterem.

A forma de agricultura praticada nas últimas quatro a cinco décadas, com a ocupação desordenada dos solos, levou-os ao empobrecimento, fazendo com que lavouras e pastagens não sejam mais lucrativas economicamente, resultando no abandono das terras.

Nessas áreas inicía-se o processo de regeneração natural, que em alguns anos atingirá a fase de capoeirinha e, ao evoluir, irá se transformar em capoeira, capoeirão e, num futuro bem distante, poderá formar novamente uma mata-clímax.

Considerando os aspectos relacionados à produção dessas áreas, as perspectivas são poucas. Entretanto, existe a possibilidade de serem introduzidas espécies florestais já nessas etapas iniciais, para que em etapas futuras a área possa ser reintegrada numa forma de uso diferente das épocas passadas, sendo o sistema agroflorestal ou silvopastoril uma grande alternativa. Uma das formas de introdução das espécies florestais de interesse pode ser por semeadura.

A canafístula é uma espécie nativa, heliófita, com boa resistência ao frio. É considerada promissora por apresentar valor econômico comprovado, em função da qualidade da madeira. O seu crescimento é rápido, classificando-a como espécie com aptidão à regeneração artificial (Carvalho, 1994). É também considerada uma espécie promissora para produção de madeira no CentroSul do Brasil (Carvalho, 1998). A madeira é utilizada na construção civil, em indústria de móveis, em construção naval, em marcenaria e carpintaria, com regular poder calorífico $(4.755 \mathrm{kcal} / \mathrm{kg})$, sendo viável para produção de papel, tendo ainda a presença de tanino na casca com teores de 6 a $8 \%$, também usada como planta medicinal e ornamental (Reitz, 1978).

A semeadura direta é uma prática comum nos Estados Unidos, em situações especiais, e guarda relação com os melhores resultados obtidos mediante plantação. $\mathrm{Na}$ América Latina existem poucos exemplos de implantação de bosques por semeadura direta. No Brasil e na

\section{R. Árvore, Viçosa-MG, v.26, n.6, p.649-654, 2002}

Argentina, a espécie de maior interesse e importância florestal para este método é a Araucaria angustifolia (Bertol.) Kuntze, tendo sido reflorestados, desta forma, cerca de 50.000 ha (Cozzo, 1976).

O sucesso da semeadura direta está na dependência da criação de um microssítio com condições tão favoráveis quanto possíveis para uma rápida germinação. Deve haver umidade suficiente durante o período de germinação e no estádio seguinte. As plantas que germinam e crescem no campo têm restrita proteção em relação aos numerosos agentes letais, os quais podem ser controlados em viveiros. Portanto, existem muito mais riscos de a sobrevivência ser baixa com o método da semeadura direta do que com o plantio de mudas (Smith, 1986). A semeadura direta, em princípio, é uma técnica recomendada somente para algumas espécies, apresentando resultados bastante favoráveis em áreas degradadas, de difícil acesso e grande declividade do terreno (Barnet \& Baker, 1991).

No início da década de 70 , cientistas dos países escandinavos já tinham começado a examinar o uso de protetores plásticos, com o objetivo de melhorar a germinação e a sobrevivência na semeadura direta e, conseqüentemente, com o objetivo de proporcionar um microambiente mais propício para germinação e crescimento das mudas jovens (Lahde, 1974). Putman \& Zasada (1986) indicaram o uso de protetores plásticos sobre os pontos em semeadura direta, realizada no Canadá, como uma técnica segura de reflorestamento.

Het (1983) utilizou pontos de semeadura direta, em solo preparado, com proteção de copos plásticos transparentes, chegando a resultados quase iguais àqueles obtidos com mudas plantadas, aos 2 anos de idade.

Na implantação de Cedrela fissilis Vell. e Pinus taeda L., por semeadura direta, Mattei (1995) concluiu que o protetor físico de pontos mostrou-se eficiente, protegendo os pontos semeados do soterramento e do ataque de algumas pragas.

Este trabalho teve por objetivo avaliar a eficiência de protetores físicos em semeadura direta de canafístula (Peltophorum dubium), no enriquecimento de capoeiras.

\section{MATERIAL E MÉTODOS}

A semeadura foi realizada no Centro Agropecuário da Palma, pertencente à Universidade Federal de Pelotas (31 ${ }^{\circ} 47^{\prime} 38^{\prime \prime}$ S e 52 $30^{\circ} 09^{\prime}$ ' W - GPS), em setembro de 
1997. As sementes de canafístula, safra 1997, PG 80\%, foram coletadas de matrizes em Pelotas-RS.

A semeadura foi realizada em área de capoeira (com altura de aproximadamente $3 \mathrm{~m}$ ), em faixas de 1,5 $\mathrm{m}$ de largura, distanciadas a $3 \mathrm{~m}$, abertas com roçadeira tracionada por trator. A altura da roçada foi de 10 a $15 \mathrm{~cm}$. A limpeza da vegetação nos pontos de semeadura foi realizada com enxada, compreendendo uma área de aproximadamente $30 \mathrm{~cm}$ de diâmetro e semeadura no centro.

Os protetores físicos utilizados como tratamentos foram copo plástico e copo de papel de aproximadamente $300 \mathrm{ml}$, sem fundo, e o laminado de madeira com tamanho semelhante ao dos copos. Ambos foram fixados sobre os pontos semeados e arranjados em blocos casualizados, com seis repetições. Cada unidade experimental teve oito pontos, distanciados de $1 \mathrm{~m}$ e semeados com três sementes cada. Previamente à semeadura, as sementes foram submetidas a tratamentos de superação de dormência, por meio de escarificação mecânica em um escarificador elétrico a 1.725 rpm, com lixa "Norton 60", por 60 segundos, e posterior embebição em água à temperatura ambiente por um período de 12 horas.

A semeadura foi manual e realizada a uma profundidade de aproximadamente $0,5 \mathrm{~cm}$. Os pontos semeados foram cobertos com uma camada de $1 \mathrm{~cm}$ de vermiculita, com a finalidade de proteção das sementes contra chuvas fortes, mantendo também a umidade nos pontos semeados.

As variáveis avaliadas foram a emergência, a sobrevivência, o número de pontos com plantas até 90 dias, a densidade um ano após a semeadura e a altura das plantas aos 18 meses. No mês de agosto de 1998, antes da retomada do crescimento, quando completou um ano da semeadura, foi realizado um raleio, deixando apenas uma planta por ponto.

A contagem da emergência foi iniciada logo que se observou a emergência das primeiras plântulas, iniciando em intervalos de três dias durante as primeiras duas semanas, passando a semanais por um mês e a cada 15 dias, até completar os 90 dias.

Os resultados foram transformados em arco-seno da raiz quadrada de $\mathrm{X} / 100$, submetidos à analise de variância e ao teste de comparação de médias.

Os principais cuidados após a implantação dos experimentos foram o controle de ervas daninhas e de formigas. $\mathrm{O}$ controle das plantas invasoras junto aos pontos de semeadura foi manual, em um círculo de aproximadamente $30 \mathrm{~cm}$ de diâmetro, realizado com o auxílio de enxada. $O$ controle de formigas foi realizado com iscas e iniciado antes da implantação do experimento.

\section{RESULTADOS E DISCUSSÃO}

A análise de variância (Quadro 1) identificou que os protetores exerceram efeitos sobre todas as variáveis avaliadas, indicando que tanto para o estabelecimento inicial como para o desempenho futuro das plantas há necessidade de criar um ambiente adequado junto aos pontos semeados.

Quadro 1 - Resultados da análise de variância da semeadura direta de canafístula (Peltophorum dubium)

Table 1 - Variance analysis results of Peltophorum dubium direct seeding

\begin{tabular}{|l|c|c|c|c|c|}
\hline Variáveis & QM & Valor F & Probabilidade F & N. Significativo & CV \\
\hline Emerg. 30 & 198,78 & 5,30 & 0,01 & $* *$ & 10,01 \\
Sobrev.. 30 & 592,91 & 8,36 & 0,001 & $* *$ & 10,85 \\
NPCPL 30 & 793,49 & 16,51 & 0,0001 & $* *$ & 9,76 \\
Emerg. 90 & 147,98 & 3,13 & 0,0506 & $*$ & 10,95 \\
Sobrev. 90 & 564,95 & 12,14 & 0,0004 & $* *$ & 10,24 \\
NPCPL 90 & $1.000,06$ & 12,39 & 0,0004 & $* *$ & 13,97 \\
PERDAS-90 & 319,12 & 4,15 & 0,024 & $* *$ & 32,81 \\
D1ANO & 933,74 & 13,48 & 0,0003 & $* *$ & \\
ALTURA & $1.526,81$ & 29,72 & 0,00002 & & $* *$ \\
\hline
\end{tabular}

Emerg. =emergência aos 30 e 90 dias; Sobrev. =sobrevivência aos 30 e 90 dias; NPCPL = número de pontos com planta aos 30 e 90 dias; PERDAS-90 = Perda total de plantas 90 dias após a semeadura; D1ANO = densidade um ano após a semeadura; ALTURA = altura das plantas aos 18 meses da semeadura; * = significância a 95\%; e ** = significância a $99 \%$. 
O baixo acréscimo na emergência ocorrida dos 30 para os 90 dias da semeadura (Quadro 2) demonstrou que para a canafístula, na semeadura realizada no mês de setembro, o maior porcentual de emergência ocorreu nos primeiros 30 dias da semeadura. Tal resultado mostra que para obtenção de sucesso em semeadura direta existe um período crítico, porém curto, que é a fase da emergência, na qual são fundamental a disponibilidade de umidade e a seguridade,o que não irá garantir que haverá prejuízos como arraste ou soterramento de sementes em caso da ocorrência de fortes chuvas. Por outro lado, após estabilizada a emergência, e mesmo durante esta, iniciamse as perdas de plântulas, que são crescentes com o passar do tempo, e se não forem tomadas as medidas adequadas pode-se chegar a uma densidade inicial que dificultará a condução do plantio nos anos subseqüentes.

Pelos resultados obtidos, constatou-se que a utilização de um protetor físico melhorou significativamente o estabelecimento das plantas em relação à testemunha, em todas as variáveis avaliadas. O protetor contribuiu tanto para o aumento na emergência como para o estabelecimento de plantas. Lahade (1974), semeando Pinus sylvestris L.; Brum (1997), semeando Pinus taeda; Mattei (1993), semeando Pinus taeda; e Putman \& Zasada (1986), Smith (1986) e Serpa (1999) também obtiveram melhores resultados quando utilizaram protetores físicos nos pontos semeados. Estas constatações estão de acordo com Smith (1986), que ressalta que o sucesso da semeadura direta dependente da criação de um microclima favorável junto aos pontos semeados.

Além do desempenho das variáveis significativamente superior onde se utilizou o protetor físico até os
90 dias da semeadura, cabe destacar que as plantas, aparentemente, apresentavam melhor crescimento, desde as fases iniciais. Tal fato pode ter sido decorrente do menor desgaste ocorrido durante a fase de germinação, pois o protetor não permitiu movimentação do solo no ponto de semeadura.

Nas avaliações realizadas até os 90 dias, os tratamentos com protetores apresentaram desempenho semelhante. Contudo, quando analisada a densidade um ano após a semeadura, pôde-se observar que onde se utilizou o protetor de papel já havia densidade inferior à do copo plástico e do laminado. O copo de papel com a umidade foi se desgastando e se decompondo, em poucos meses. A partir de dezembro de 1997, ocorreu uma estiagem com altas temperaturas. Aparentemente no protetor plástico ocorreu maior aquecimento, visto que nas linhas abertas na capoeira incidia sol e as plantas apresentavam aspectos de maior deficiência de umidade. No laminado, devido às suas características, aparentemente a condição pode ter sido mais amena. Lahade \& Tuohisaari (1976) observaram aumento da temperatura e da umidade dentro dos protetores de plástico, favorecendo a germinação.

Quando a altura das plantas foi avaliada, ou seja, aos 18 meses após a semeadura (abril de 1999, início da fase de repouso) (Figura 1), constatou-se que aquelas originadas onde o protetor físico utilizado foi o laminado de madeira apresentaram altura significativamente superiores à dos demais tratamentos. A possível razão deste maior desempenho pode estar fundamentada na fase inicial, que impulsionou o melhor desempenho das etapas subseqüentes. Entretanto, em novos estudos poderá ser

Quadro 2 - Efeito de protetores físicos sobre o estabelecimento e crescimento de canafístula (Peltophorum dubium), 18 meses após a semeadura direta, no enriquecimento de capoeiras

Table 2 - Physical shelter effects on the establishment and initial development of Peltophorum dubium, 18 months after direct seeding on shrubs

\begin{tabular}{|c|c|c|c|c|c|c|c|c|c|}
\hline \multirow{2}{*}{$\begin{array}{c}\text { Fonte } \\
\text { Variação }\end{array}$} & \multicolumn{2}{|c|}{ Emergência (dias) } & \multicolumn{2}{|c|}{ Sobrevivência (dias) } & \multicolumn{2}{|c|}{ NPCplantas (dias) } & \multirow{2}{*}{$\begin{array}{c}\text { Perd. (dias) } \\
90\end{array}$} & \multirow{2}{*}{$\begin{array}{l}\text { Dens. } \\
\text { (ano) }\end{array}$} & \multirow{2}{*}{$\begin{array}{l}\text { Alt. } \\
(\mathrm{cm})\end{array}$} \\
\hline & 30 & 90 & 30 & 90 & 30 & 90 & & & \\
\hline TEST & $63,6 \mathrm{~b}$ & $69,6 \mathrm{~b}$ & $79,3 \mathrm{~b}$ & $63,4 \mathrm{~b}$ & $65,1 \mathrm{~b}$ & $51,6 \mathrm{~b}$ & $36,4 \mathrm{a}$ & $29,1 \mathrm{~b}$ & 28,7 c \\
\hline PLA & 79,4 a & $80,2 \mathrm{ab}$ & 99,1 a & $84,4 \mathrm{a}$ & 95,7 a & 86,0 a & $18,7 \mathrm{~b}$ & $66,4 \mathrm{a}$ & $41,4 \mathrm{~b}$ \\
\hline PAP & 83,9 a & 86,7 a & $98,3 \mathrm{ab}$ & $91,1 \mathrm{a}$ & 94,3 a & $94,3 \mathrm{a}$ & $16,3 \mathrm{~b}$ & $45,2 \mathrm{~b}$ & $36,0 \mathrm{bc}$ \\
\hline LAM & $78,0 \mathrm{a}$ & $78,1 \mathrm{ab}$ & $97,0 \mathrm{ab}$ & $92,3 \mathrm{a}$ & $94,0 \mathrm{a}$ & $84,4 \mathrm{a}$ & $11,9 \mathrm{~b}$ & $75,7 \mathrm{a}$ & $65,5 \mathrm{a}$ \\
\hline
\end{tabular}

Médias seguidas por letras distintas nas colunas diferem entre si a 5\%, pelo teste de Tukey. NPCplantas = número de pontos com plantas aos 30 e 90 dias; Perd. = perdas de plantas; Dens. = densidade um ano após a semeadura; Alt. = altura das plantas 18 meses após a semeadura; PLA = protetor copo plástico; PAP = protetor copo de papel; e LAM = protetor laminado de madeira. 
observada a possível eficiência superior do laminado como protetor, visto que em semeadura direta de Pinus taeda Mattei (1997) não foram obtidas diferenças quando o copo plástico e o laminado foram utilizados como protetores.

As formigas, em maior intensidade, e também outros insetos constituíram-se em adversidades à semeadura direta, sendo os danos localizados e independentes da existência de protetor. A utilização de um protetor físico demonstra ser eficiente perante as adversidades ambientais, porém pouco sobre as biológicas.

O controle de formigas deve ser contínuo, com vistorias constantes, não podendo haver descuidos mesmo que haja baixo nível de incidência. Os prejuízos causados por formigas podem ser elevados em semeadura direta, pela simples razão de que logo após a emergência as plântulas são muito pequenas e facilmente eliminadas, mesmo antes de se poder tomar as devidas medidas de controle. Na condição de semeadura em capoeiras, a dificuldade é ampliada, devendo as observações serem mais freqüentes do que em situação de campo aberto.

Na testemunha, as plantas, mesmo não sendo eliminadas, foram mais danificadas pelas pragas (formigas e outros insetos), podendo ser esta uma das razões da menor densidade um ano após a semeadura. A maior dificuldade na emergência como conseqüência da erosão e, ou, soterramento debilitou algumas plantas, deixando-as mais suscetíveis ao tombamento.

Neste experimento, optou-se por não utilizar qualquer tratamento de sementes, porém sabe-se que uma semente após a escarificação mecânica sempre fica mais sujeita à ação de organismos patogênicos. Portanto, a ocorrência de tombamento não esteve associada ao uso ou tipo de protetor físico, pois não houve diferenças significativas entre os tratamentos (a análise realizada não consta nos quadros), dependendo exclusivamente da fonte de inóculo da semente e do solo.

Para uma maior população de plantas no método de semeadura direta, é necessário que se trabalhe com atenção redobrada, principalmente na fase inicial de estabelecimento, pois as maiores perdas acontecem na fase de plântula, quando o ataque de insetos é fatal para a maioria das plantas.

Segundo Shimizu (1998), existem várias razões para se incorporar a silvicultura na propriedade, e a decisão sobre as espécies a serem plantadas deve ser tomada de acordo com as oportunidades e limitações que cada propriedade apresenta.

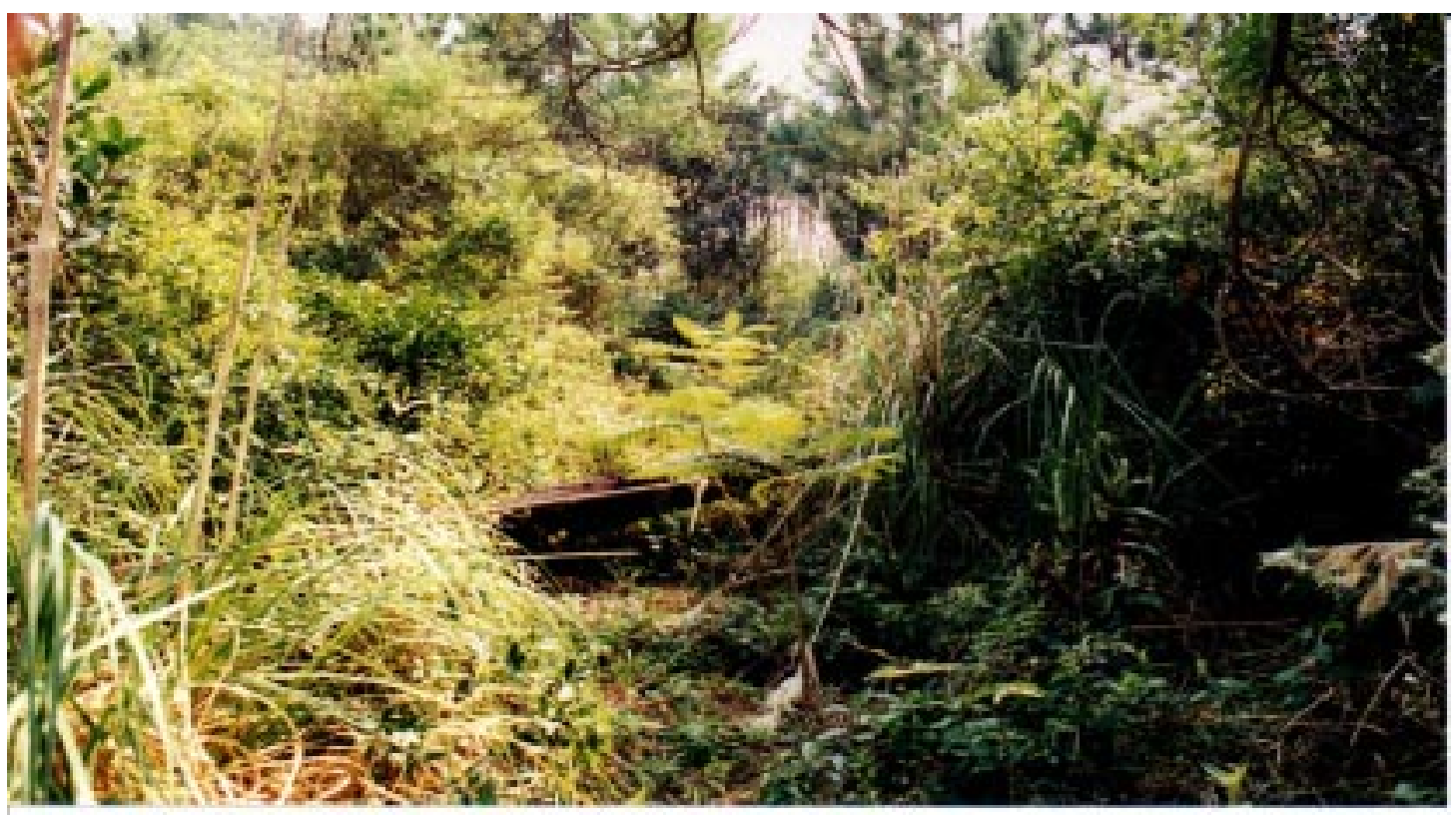

Figura 1 - Vista da área e das plantas de Peltophorum dubium, 18 meses após a semeadura.

Figure 1 - General view of Peltophorum dubium plants, 18 months after direct seeding. 
Nesse sentido, a canafístula mostrou grande potencial para ser utilizada em semeadura direta, devendo ser estudados tratamentos de pré-semeadura que visem tornar o método eficiente e simples, de forma que num futuro próximo possa ser recomendado para o agricultor.

\section{CONCLUSÕES}

A semeadura direta de canafístula (Peltophorum dubium) pode ser utilizada como forma de enriquecer áreas de capoeira.

Os protetores físicos em pontos de semeadura expressam efeitos benéficos sobre a emergência, sobrevivência e densidade inicial em semeadura direta.

O laminado de madeira, por ser degradável e de custo reduzido, é o protetor recomendado.

\section{REFERÊNCIAS BIBLIOGRÁFICAS}

BARNETT, J. P.; BAKER, J. B. Regeneration methods. In: DUREYA, L.; DOUGHERTY, P.M.; PHILIP, M., (Eds.) Forest regeneration manual. Dordrecht: Kluver, 1991. p. 35-50.

BRUM, E.S. Emergência de Pinus taeda L. em semeadura direta a diferentes profundidades. Pelotas: Universidade Federal de Pelotas, 1997. 53 p. Dissertação (Mestrado em Sementes) - Universidade Federal de Pelotas, 1997.

CARVALHO, P. E. R. Espécies florestais brasileiras: recomendações silviculturais, potencialidade e uso da madeira. Colombo: EMBRAPA-CNPF; Brasilia: EMBRAPA-SPI, 1994. 640 p.

CARVALHO, P. E. R. Espécies nativas para fins produtivos. In: CARVALHO, P. E. R. Espécies não tradicionais para plantios com finalidades produtivas e ambientais. Colombo: EMBRAPA CNPF, 1998. p. 103-125.

COZZO, Domingo. Tecnologia de la florestacion en Argentina y America Latina. Buenos Aires: Hemisfério Sur, 1976. $610 \mathrm{p}$.

HET, D. Spot sowing of Mediterranean pines under shelter. Tree Planters' Notes, v. 34, n. 4, p. 23-27, 1983.
LAHDE, E. The effect of seed-spot shelters and cold stratification on pine (Pinus sylvestris L.). Folia Forestalia. Ins. For. Fenn., n. 196, p. 1-16, 1974.

LAHDE, E.; TUOHISAARI, O. An ecological study on effects of shelters on germination and germling development of scots pine, norway spruce and siberian larch. Helsinki: Communications Institututi Forestalis Fenniae, v. 88, n. 1, 1976. 37 p.

MATTEI, V. L. Avaliação de protetores físicos em semeadura direta de Pinus taeda L. Ciência Florestal, v. 7, n. 1, p. 91-100, 1997.

MATTEI, V. L. Comparação entre semeadura direta e plantio de mudas produzidas em tubetes, na implantação de povoamentos de Pinus taeda L. Curitiba: UFPR, 1993. 149 p. Tese (Doutorado em Engenharia Florestal) Universidade Federal do Paraná, 1993.

MATTEI, V. L. Preparo de solo e uso de protetor físico, na implantação de Cedrela fissilis Vell. e Pinus taeda L., por semeadura direta. Revista Brasileira de Agrociência, v. 1, n. 3, p. 133-136, 1995.

PUTMAN, W. E.; ZASADA, J. C. Direct seeding techniques to regenarate white spruce in interior Alaska. Canadian Journal Forest Research, v. 16, p. 660-664, 1986.

REITZ, R.; KLEIN, R. M.; REIS, A. Projeto madeira de Santa Catarina. Sellowwia, n.34/35, p. 525, 1978.

SERPA, M. R. Avaliação de diferentes materiais de cobertura no estabelecimento de plantas de Pinus taeda L. no sistema de semeadura direta. Pelotas: Universidade Federal de Pelotas, 1999. 49 p. Dissertação (Mestrado em Agronomia) - Universidade Federal de Pelotas, 1999.

SHIMIZU, J. Y. Espécies não tradicionais para plantios com finalidades produtivas e ambientais: Silvicultura e Usos. In: Espécies não Tradicionais para Plantios com Finalidades Produtivas e Ambientais. Colombo: EMBRAPA CNPF, 1998. p. 63-71.

SMITH, D. M. The practice of silviculture. 8.ed. New York: John Wiley, 1986. 610 p. 